\title{
O YOUTUBE COMO INSTRUMENTO DE ESTÍMULO AO PROCESSO DE APRENDIZAGEM NAS UNIVERSIDADES
}

\section{YOUTUBE AS AN INSTRUMENT OF STIMULATION TO THE LEARNING PROCESS IN} UNIVERSITIES

\author{
EL YOUTUBE COMO INSTRUMENTO DE ESTÍMULO AL PROCESO DE APRENDIZAJE EN \\ LAS UNIVERSIDADES
}

\author{
Fernando Miguel Teixeira da Silva Coelho
}

Universidade Católica Portuguesa, Braga, Portugal. E-mail: fernandocoelho.publicidade@gmail.com

\author{
João Batista Bottentuit Junior
}

Doutor em Ciências da Educação. Professor - Universidade Federal do Maranhão. E-mail: jbbj@terra.com.br

\section{RESUMO}

Educar pode ser compreendido como um processo de formação destinado a desenvolver o indivíduo com conhecimento dotá-lo de habilidades e competências que o torne capaz de participar de maneira produtiva da sociedade. Para Neves (2007), até os anos 80 existia certo consenso global de que você aprendia nas instituições de ensino; todavia, como o advento da tecnologia, a sociedade se transformou e a maneira de aprender reconfigurou-se neste contexto. Na cultura digital o aluno é considerado membro ativo do processo de aprendizado e inclusive por horas, autor do processo. Neste artigo será apresentado o recorte de uma pesquisa de campo realizada em uma universidade maranhense com alunos do curso superior, da graduação de comunicação social, onde buscou-se identificar o nível de aprendizagem por meio de ferramentas TIC (tecnologias da informação e comunicação), sendo uma destas, o vídeo, tendo-se como recurso de ambiente virtual o Youtube.

Palavras-chave: Redes sociais. Cultura digital. Vídeo educativo.

\section{ABSTRACT}

Educating can be understood as a process of formation aimed at developing the individual with knowledge to equip him with skills and competences that make him able to participate productively in society. For Neves (2007), until the 1980 s there was some global consensus that you learned in educational institutions; however, as the advent of technology, society has transformed and the way of learning has been reconfigured in this context. In digital culture the student is considered an active member of the learning process and even for hours, author of the process. This article will present a study of a field research carried out at a university in Maranhão, Brazil, with undergraduate students from undergraduate and graduate programs in social 
communication, where it was possible to identify the level of learning through ICT tools, being one of these, the video, having as a virtual environment YouTube.

Keywords: Social networks. Digital culture. Educational video.

RESUMEN

Educar puede ser comprendido como un proceso de formación destinado a desarrollar al individuo con conocimiento dotándolo de habilidades y competencias que lo haga capaz de participar de manera productiva de la sociedad. Para Neves (2007), hasta los años 80 existía cierto consenso global de que usted aprendía en las instituciones de enseñanza; sin embargo, como el advenimiento de la tecnología, la sociedad se transformó y la manera de aprender se reconfiguró en este contexto. En la cultura digital el alumno es considerado miembro activo del proceso de aprendizaje e incluso por horas, autor del proceso. En este artículo se presentará el recorte de una encuesta de campo realizada en una universidad maranhense con alumnos del curso superior, de la graduación de comunicación social, donde se buscó identificar el nivel de aprendizaje a través de herramientas TIC (tecnologías de la información y comunicación), siendo una de éstas, el vídeo, teniendo como recurso de ambiente virtual el Youtube.

Palabras clave: Redes sociales. Cultura digital. Vídeo educativo.

\section{INTRODUÇÃO}

A interação com as tecnologias dentro de sala de aula permite a alunos e professores melhor aproveitamento do tempo e conteúdo, uma vez que as aulas se tornam mais instigantes e dinâmicas, fazendo também com que o aluno seja parte ativa do processo de construção e não apenas um mero receptor. Vale aqui também um recorte reflexivo peculiar, a sala de aula não é mais o único ambiente de compartilhamento de saber; outros ambientes, agora virtuais, também passam a compor este cenário de aprendizagem, como por exemplo, plataformas digitais, aplicativos, grupos de mensagens instantâneas, etc. No processo educativo dos nossos dias, o ensino apoiado pelas TIC's é considerado por alguns professores, como um auxílio paralelo a uma ferramenta que exerce determinada função numa sala de aula.

As TIC's em sala de aula devem ser compreendidas como um meio de modernização e intercâmbio de experiências entre alunos e professores onde cada um pode contribuir com o processo cognitivo do outro por meio de trocas relevantes na transmissão e construção do conhecimento. O uso de dispositivos digitais deve ser compreendido como um elemento didático que favoreça o processo de ensino aprendizagem proporcionando ao aluno a obtenção de informações complementares que favoreçam o debate e reflexão, 
adequando à sua realidade e permitindo a criação de novos contextos.

Segundo Valente (2012), à formação cabe hoje o papel norteador, para superação das crises do trabalho, transitando do homo studiosus para homo universalis. Visto tal ponderação, é preciso perceber o aluno com um ator social presente em um ambiente global de competitividade, sendo o papel do professor e da universidade inseri-lo neste contexto com preparo autêntico. Assim, no espaço acadêmico, o professor deve proporcionar condições para que o aluno aprenda de forma autônoma e as ferramentas de tecnologias da informação e comunicação aplicadas à educação são, portanto, uma ótima estratégia para o alcance desse objetivo.

O desafio de desenvolver pessoas para o mundo e mercado na era contemporânea inclui não apenas melhorar a educação formal, mas também conectá-la a uma educação digital. Dessa maneira faz todo sentido analisar a educação formal e educação digital articuladamente.

Na cultura digital o aluno é considerado membro ativo do processo de aprendizado e inclusive por horas, autor do processo. Lévy (2009, p. 28) sinaliza que a inteligência tornouse coletiva e distribuída em partes e por toda a parte. Dessa forma, o aluno consegue tranquilamente e qualitativamente aprender em diversos ambientes: sala de aula, blogs, dispositivos mobiles, plataformas de vídeos, entre outros.

O Youtube é um site de vídeos, lançado em 2005 por Steve Chen, Chad Hurley e Jawed Karin, tendo como proposta ser uma plataforma de compartilhamento de vídeos na internet. Para Burgess e Green (2009) o Youtube pode ser denominado como um ambiente de cultura popular participativa, sendo hoje a maior aglutinadora de mídia popular e empresarial de massa na internet.

De acordo com dados divulgado pelo Portal TechMundo, a plataforma é acessada por $95 \%$ da população online brasileira ao menos uma vez por mês. Ao analisar o perfil deste usuário percebe-se que $96 \%$ são jovens entre 18 a 35 anos, $87 \%$ concordam que a plataforma permite o consumo de qualquer tipo de conteúdo, quando e onde quiserem, 96\% dos usuários acessam a internet todos os dias, principalmente por meio do smartphone (82\%) e do computador (66\%). 
Segundo dados do próprio Youtube, a página possui hoje mais de 1 bilhão de usuários, em dispositivos móveis alcança na sua maioria pessoas entre 18 e 34 anos, está presente em 88 países. A partir dessa perspectiva, fica um questionamento chave: como o Youtube pode contribuir com o processo de aprendizagem no ensino superior?

Youtube como instrumento de estímulo ao processo de aprendizagem

O significado de saber mudou. Isso nos mostra uma nova dinâmica no processo aprendizado. O aluno universitário, mais tarde profissional de mercado, em vez de ser capaz de lembrar e repetir informações, deve ser capaz de saber como encontrá-las e usálas, haja vista que, hoje qualquer informação está ao alcance de todos no universo digital.

Mais do que transmitir um conteúdo, o professor contemporâneo deve ser capaz de instigar, estimular e despertar no aluno o interesse não apenas pelo aprendizado, mas, pela busca autônoma. A sala de aula não deve ser compreendida como um espaço rígido, cheio de regras e com conteúdo limitado. A informação não deve ser limitada, mas sim, democratizada como hirpelinks textuais e conexões cognitivas. Fava (2014) afirma que na educação 3.0, a escolha não se pautará mais por disciplinas ou unidades de aprendizagem.

Mais do que transmitir um conteúdo, o professor contemporâneo deve ser capaz de instigar, estimular e despertar no aluno o interesse não apenas pelo aprendizado, mas, pela busca autônoma. A sala de aula não deve ser compreendida como um espaço rígido, cheio de regras e com conteúdo limitado. A informação não deve ser limitada, mas sim, democratizada como hirpelinks textuais e conexões cognitivas. Fava (2014) afirma que na educação 3.0, a escolha não se pautará mais por disciplinas ou unidades de aprendizagem.

Educar pode ser compreendido como um processo deformação destinado a desenvolver o indivíduo com conhecimento, dotá-lo de habilidades e competências que o torne capaz de participar de maneira produtiva da sociedade. Para Neves (2007), até os anos 80 existia certo consenso global de que você aprendia nas instituições de ensino; todavia, como o advento da tecnologia, a sociedade se transformou e a maneira de aprender reconfigurou-se neste contexto. Na cultura digital o aluno é considerado membro ativo do processo de aprendizado e inclusive por horas, autor do processo. Lévy (2009, p. 28) 
sinaliza que a inteligência tornou-se coletiva e distribuída em partes e por toda a parte. Dessa forma, o aluno consegue tranquilamente e qualitativamente aprender em diversos ambientes: sala de aula, blogs, dispositivos mobiles, plataformas de vídeos, entre outros.

O Youtube é um site de vídeos, lançado em 2005 por Steve Chen, Chad Hurley e Jawed Karin, tendo como proposta ser uma plataforma de compartilhamento de vídeos na internet. Para Burgess e Green (2009) o Youtube pode ser denominado como um ambiente de cultura popular participativa, sendo hoje a maior aglutinadora de mídia popular e empresarial de massa na internet.

De acordo com dados divulgado pelo Portal TechMundo, a plataforma é acessada por $95 \%$ da população online brasileira ao menos uma vez por mês. Ao analisar o perfil deste usuário percebe-se que $96 \%$ são jovens entre 18 a 35 anos, $87 \%$ concordam que a plataforma permite o consumo de qualquer tipo de conteúdo, quando e onde quiserem, 96\% dos usuários acessam a internet todos os dias, principalmente por meio do smartphone (82\%) e do computador (66\%).

Segundo dados do próprio Youtube, a página possui hoje mais de 1 bilhão de usuários, em dispositivos móveis alcança na sua maioria pessoas entre 18 e 34 anos, está presente em 88 países.

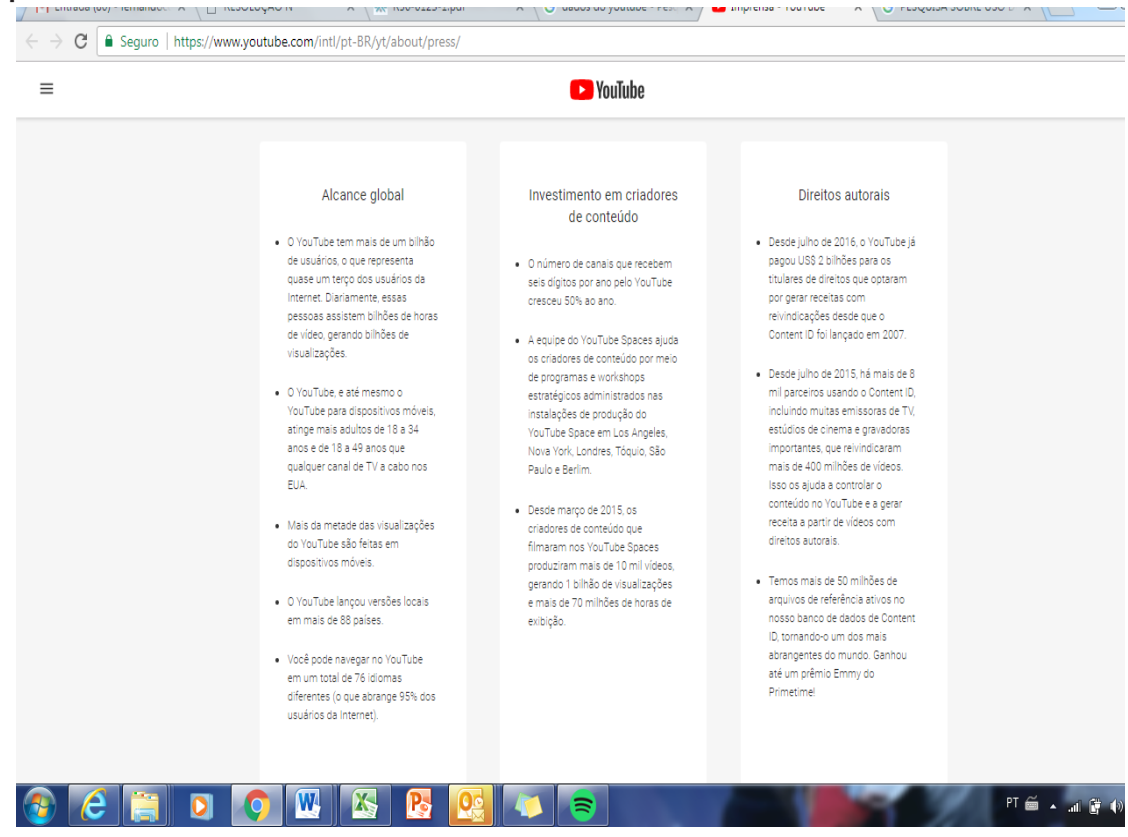

Figura 1 - Dados do Youtube 
Fonte: https://www.youtube.com/intl/pt-BR/yt/about/press/

Frente a estes dados não se pode, portanto, deixar de contemplar-se tal ferramenta como um instrumento de educação nas salas de aula. O Youtube proporciona um aprendizado experiencial e dinâmico que, melhora a cognição do interlocutor dado o seu caráter visual e auditivo.

Para Morán (2000, p. 11), a forma tradicional de ensino, onde o educador é em muitos momentos um simples transmissor do conhecimento, passa por mudança e tanto professores como alunos têm a sensação de que muitas aulas convencionais estão ultrapassadas. Ao utilizar o Youtube, o professor se insere na realidade midiática do aluno, ganha mais proximidade, interage melhor e consegue incluir temáticas relevantes para discussão em sala de aula. Outro ponto que vale destaque é que assim como outras ferramentas de tecnologia da informação e comunicação, a plataforma de vídeo facilita a assimilação da matéria e torna o ensino e o aprendizado algo mais prazeroso tanto para os emissores quanto para os receptores envolvidos no processo.

Estamos em um momento histórico do predomínio da imagem e da interatividade que podem ser incorporadas aos recursos utilizados para ensinar, permitindo que a realidade do aprendiz seja cada vez mais próxima e coerente com o seu cotidiano já permeado de sons, cores, dinamismo e informações (BASSO, 2009, p. 52).

Morán (1993, p. 3) complementa ainda que muitas vezes, “a escola desvaloriza a imagem e toma as linguagens audiovisuais como negativas para o conhecimento. Ignora a televisão, o vídeo; exige somente o desenvolvimento da escrita e do raciocínio lógico.”.

É perceptível a veracidade dessa informação quando um colega docente sente-se incomodado ao flagrar um aluno portando celular em sala de aula, realidade que não se pode mais alterar. Neste momento, o mais recomendável é pensar maneiras de inserir o dispositivo no processo de aprendizagem e estimular a participação ativa e colaborativa. A utilização do vídeo trabalha os aspectos sensoriais, visual, linguagem falada, linguagem musical e escrita.

As linguagens presentes no vídeo são diversas e interagem superpostas, interligadas, somadas, não separadas. Para Morán (1993) aí está a sua força. O ser humano é atingido 
por todos os sentidos, nesta perfectiva, o vídeo como instrumento educacional seduz, informa, entretém e projeta o aluno em outras realidades (no imaginário), em outros tempos e espaços.

Ao inserir o Youtube como instrumento de ensino e como recurso de apoio as aulas, o docente consegue como resultado: melhor retenção do conteúdo, aprendizagem baseada na experiência, despertar o interesse discente, hiperconexão textual e engajamento na disciplina. Para Andrade (2007) o uso de vídeos em sala de aula agrega valores contemporâneos de ensino e alguns pontos devem ser considerados na seleção deste recurso durante o planejamento das aulas:

1. Analisar os pontos positivos e negativos do vídeo além do contexto e enredo é fundamental para a escolha do vídeo mais adequado;

2. Observar se as imagens despertarão a criticidade do aluno e sua reflexão;

3. Verificar a faixa etária dos alunos para a linguagem e imagem do vídeo a ser exibido;

4. Buscar contextualizar o vídeo com as atividades e exercícios propostos;

5. Verificar a qualidade do áudio e do vídeo, a qualidade do equipamento, duração do tempo da aula e do vídeo;

6. Observar os elementos do vídeo como imagens, cores, texto e linguagem;

7. Evitar a utilização dos vídeos apenas para cumprir a carga horária e informar aos alunos que o vídeo é uma das inúmeras ferramentas que podem ser utilizadas em sala de aula para o ensino e aprendizagem.

Os vídeos quando utilizados pelo docente podem ser aproveitados em plataforma digital fora ou dentro da sala de aula. É comum, por exemplo, que docentes que se utilizem desse recurso realizando download do material ou ainda abrindo em no próprio ambiente para expor para a turma. Outra possibilidade é empregar o vídeo como recurso extraclasse e material complementar. A utilização dos vídeos do Youtube auxilia na construção de novos conhecimentos, a educação e a reeducação audiovisual, dinamiza o olhar do aluno, a criticidade, a reflexão, o estimula a pesquisa, o compartilhamento de experiências, as competências individuais e também o trabalho em grupo. 
O site também permite um grau elevado de interatividade, conforme sinaliza Kamers (2013) ao ponderar que o modo interativo e inteligente pelo qual os vídeos são disponibilizados facilita a localização dos mesmos, seja por assunto, afinidade com o objeto da pesquisa ou com os autores do vídeo em questão. Segundo Carvalho e Gonçalves (2000), a utilização do vídeo traz a emoção e a sensibilidade do aluno à tona, pois, as imagens tornam-se mais vívidas e falam por si só, exaltando assim, a reflexão crítica do que está sendo observado.

Para este estudo especifico e análise de campo, observou-se o uso do canal desenvolvido pelo docente: https://www.youtube.com/canalfernandocoelho

O canal no Youtube foi utilizado como ferramenta complementar de estudo aos conteúdos ministrados pela disciplina. Para o desenvolvimento do mesmo utilizou-se toda uma estratégia de seleção de tema, construção do material e desenvolvimento do conteúdo.

O ambiente é alimentado semanalmente com temas que são abordados direto ou indiretamente em sala de aula, com a participação do docente e profissionais de mercado,

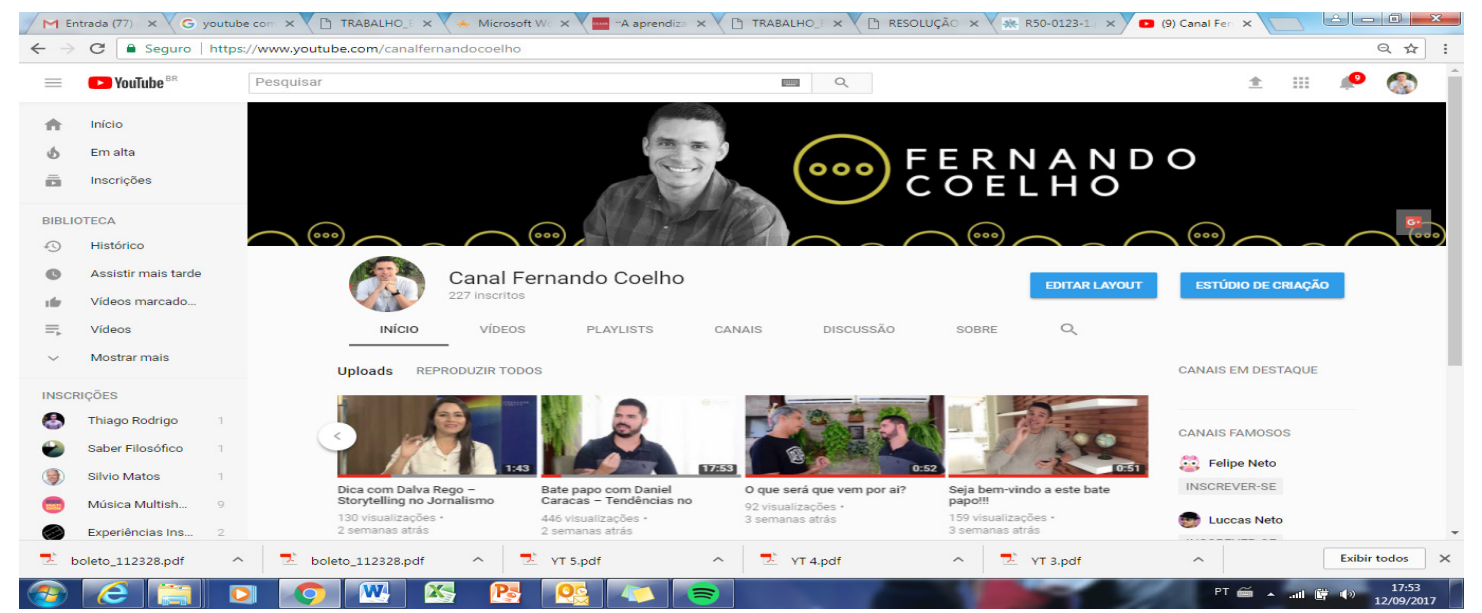

Figura 2 - Tela de abertura do Canal Fernando Coelho

Para que a experiência do usuário se torne positiva o docente deve pensar em detalhes que proporcione uma navegação positiva do aluno. Abaixo se listam pontos importantes:

Identidade visual do canal - é fundamental que a página possua um aspecto estético atraente e que converse com o público foco. 
Tema - é preciso definir de forma adequada e centrado no público foco o conteúdo editorial a ser abordado.

Formato - faz-se também necessário a definição do formato editorial, definindo o tempo dos vídeos, os recursos multimídia e texto a ser utilizado.

Continuidade - o que torna uma página relevante para o público jovem é a frequência de postagem do conteúdo, que precisa ser definida também no planejamento.

Para o desenvolvimento da página específica o docente seguiu as etapas do PDCA já citada neste trabalho e descrita no quadro que segue:

\begin{tabular}{|l|l|}
\hline PLAN & $\begin{array}{l}\text { Planejamento do formato, conteúdo, linha editorial, identidade visual, } \\
\text { estratégia de lançamento, divulgação do canal para o público foco, seleção } \\
\text { do espaço de gravação, captação de parceiro audiovisual, definição de } \\
\text { cronograma de gravação e postagem. }\end{array}$ \\
\hline DO & \begin{tabular}{l} 
Execução do planejamento conforme desenhado. \\
\hline CHECK
\end{tabular} \\
\hline ACTION & $\begin{array}{l}\text { Ação corretiva com base nos indicadores de performance dos vídeos e } \\
\text { feedbacks recebido. }\end{array}$ \\
\hline
\end{tabular}

Utilizando o Youtube como um objeto de aprendizagem, é possível planejar e trabalhar da melhor maneira possível o conteúdo em sala de aula, maximizando o planejamento pedagógico e agregando valores ao ensino e aprendizagem. De acordo com Martín-Barbero (2001), a plataforma de vídeo já faz parte da realidade, e por meio dela, surge novas problemáticas que envolvem complexidades no que se refere à comunicação na sociedade atual e principalmente quando se visa o processo educativo.

Ao utilizar a mídia digital na educação, o docente está reforçando competências contextualizadas à sociedade contemporânea, remodelando inclusive a maneira de observar e produzir conhecimento e saberes.

Por exemplo, um aluno da disciplina de Marketing, do Curso de Publicidade e Propaganda que é exposto ao conteúdo sobre tendências de mercado, pode complementar a aprendizagem assistindo a uma entrevista direcionada pelo docente no Youtube, assim, o aluno refletirá de forma 
objetiva e contextualizada sobre a temática. Na imagem abaixo, observa-se este exemplo de maneira clara, onde, o professor, como parte do processo de ensino, realiza uma entrevista com um especialista da área que compartilha sua experiência de atuação.

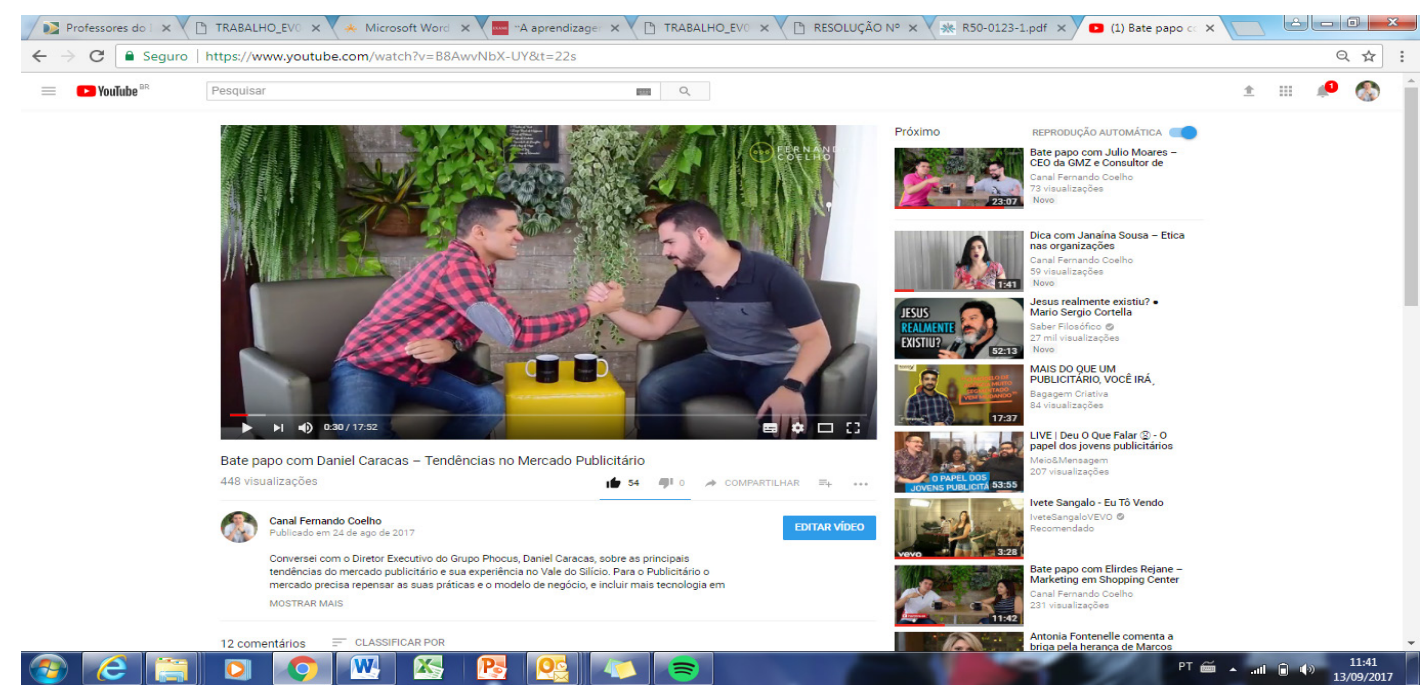

Figura 3 - Canal no Youtube, entrevista com especialista de mercado

Na entrevista acima, o professor inserido na realidade midiática do aluno, entrevista um profissional de mercado de renome da região, que compartilha com uma linguagem acessível e dinâmica práticas de mercado e reflexões sobre tendências. Dessa maneira, essa metodologia permite ao discente associar conteúdos trabalhados em sala de aula com exemplos sinalizados pelo profissional, colaborando diretamente para edificação cognitiva do saber.

O vídeo em questão no dia 13/09/2017 possuía 448 visualizações, 54 curtidas e 12 comentários. Vale destacar que a sala de aula estudada possuía apenas 50 alunos, dessa maneira é possível afirmar que, o material impacta e corrobora também com o desenvolvimento de outros atores sociais.

Pelo ambiente selecionado para composição do cenário, estilo editorial do canal e conteúdo abordado o aluno se sente atraído pelo material e instigado a assistir, complementando assim a sua formação.

Escaneando o QR Code abaixo épossível assistir na integra a entrevista disponibilizada no canal educativo do docente. 


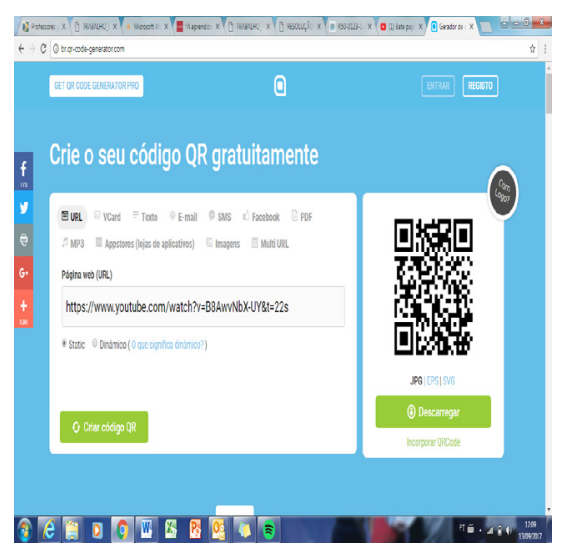

Figura 4-QR Code com programa, entrevista com especialista de mercado

O segundo vídeo que ilustra essa temática é também uma entrevista com uma especialista de mercado, que aborda o tema Marketing de Varejo e Experiência de Compra, assunto abordado em sala e disponibilizado ao aluno como complemento.

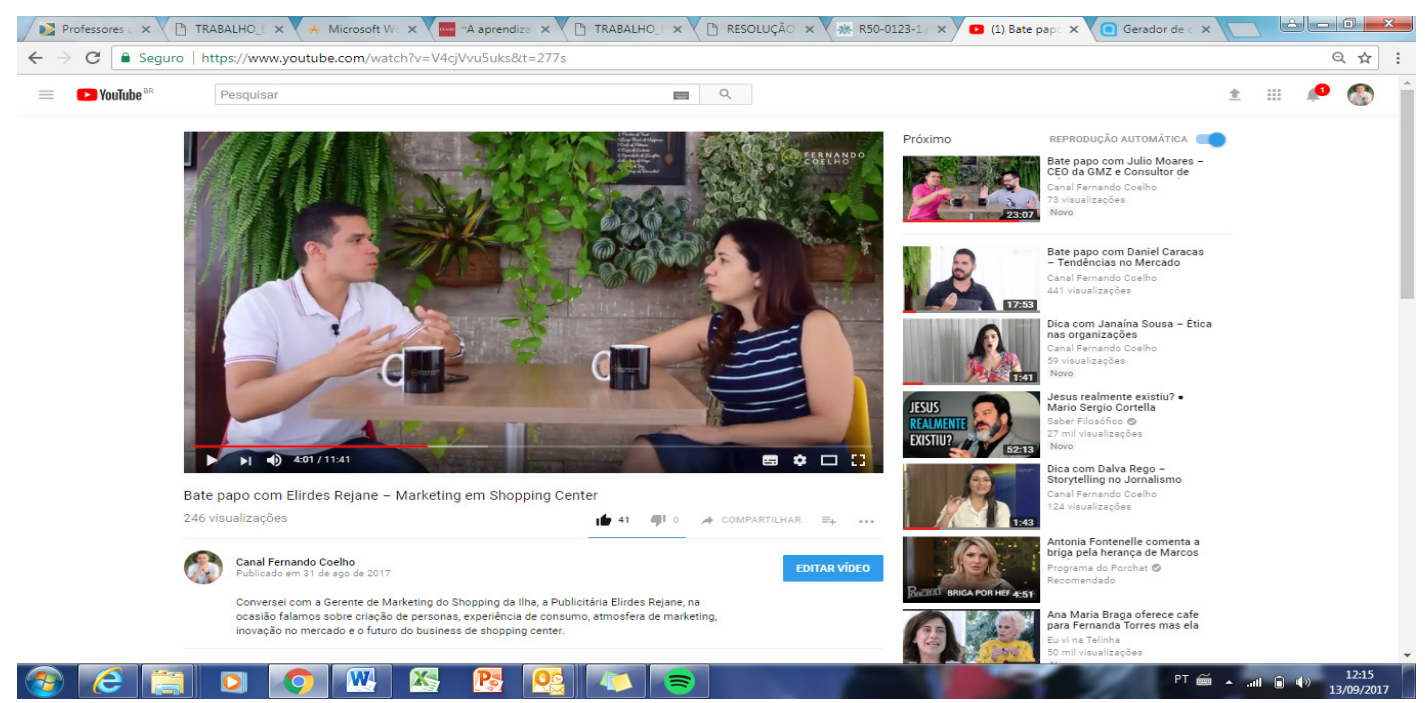

Figura 5 - Canal no Youtube, entrevista com especialista em varejo

O material acessado no dia 13/09/2017 apresentou como performance 246 visualizações e 46 curtidas.

Levando-se em consideração ambos os materiais apresentados como exemplo e uma sala de aula composta por 50 alunos, pode-se afirmar que $100 \%$ do grupo foi impactado, gerando reverberação também em outros atores sociais. 


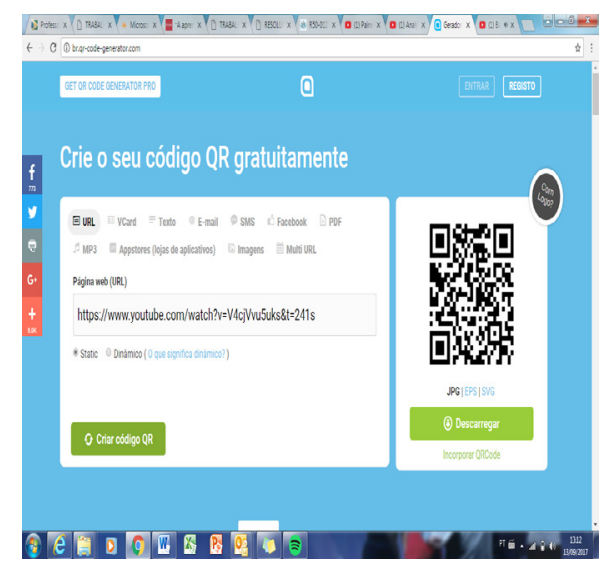

Figura 6 - QR Code, entrevista com especialista em varejo

No QR Code acima é possível acessar o vídeo contendo a entrevista completa onde a especialista explica detalhes sobre marketing de varejo, experiência de consumo e outras temáticas associadas as aulas.

Na metodologia PDCA, na etapa de acompanhamento é fundamental que o docente como parte de sua estratégia, metrifique o resultado do material publicado. A própria página disponibiliza um ambiente com estatísticas dos vídeos que pode ser utilizado para redefinir ou ajustar o conteúdo trabalhado e/ou conhecer melhor o perfil do público foco.

Para Chamuzca (2011) é fundamental que o profissional atuante no ambiente digital possua em mãos todas as métricas necessárias para avaliar o resultado da ação, de forma que, durante o desenvolvimento já se possam aplicar medidas de desempenho do sucesso.

A mensuração leva ao controle e, eventualmente, a melhoria. Uma máxima de mercado sinaliza que se, não se puder medir algo, será impossível entende-lo. Se não possuir entendimento, não poderá controlá-la. Se não puder controlá-la, não conseguirá melhorá-la. É indispensável em qualquer ação online ou off-line a avaliação dos resultados para uma melhor gestão pedagógica.

Para Chamuzca (2011, p. 88) deve-se mensurar no ambiente digital e isso inclui as plataformas que são usadas com finalidades educacionais:

a) taxa de rejeição de um site - o percentual de visitantes que deixaram o site na primeira página;

b) tempo de navegação o tempo que o visitante passou dentro do site;

c) conversões em vendas relação entre o número de visitantes e o volume de vendas 
obtido;

d) geração de tráfego de onde chegam os visitantes do site;

e) número de impressões e quantidade de vezes que foi visualizado pelos visitantes;

f) número de visitantes únicos em um site quantidade real de visitantes que acessou o site. Um mesmo visitante pode acessar um determinado site várias vezes e todas elas são contabilizadas. Em geral, os sistemas verificam a unicidade do visitante pelo seu número IP;

h) monitoramento de menções e comentários em mídias sociais análise mais complexa.

Com base nestes itens sinalizados, chamados de indicadores, é possível analisar a eficiência de um material publicado em uma plataforma digital utilizada pelo professor. $\mathrm{Na}$ figura abaixo é possível identificar métricas que corroboram com a avaliação de cada vídeo e performance da página:

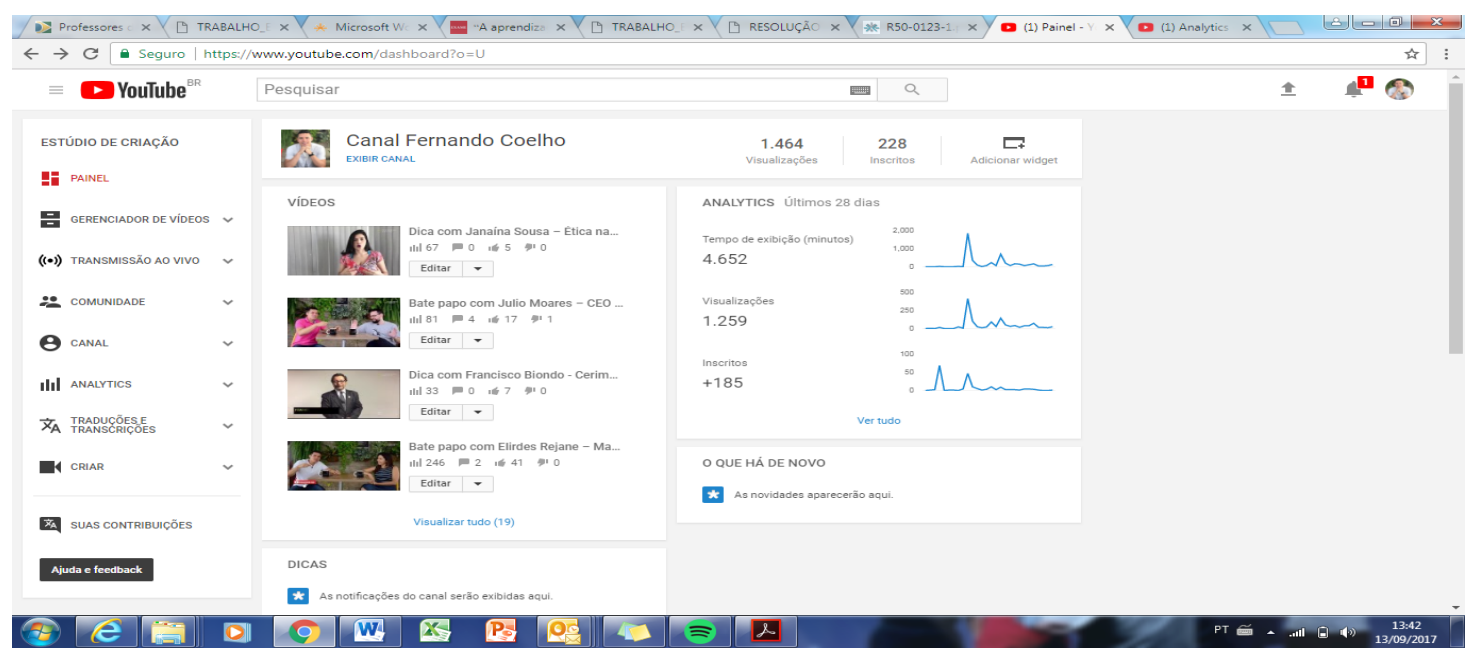

Figura 7 - Painel de indicadores da página de vídeo

No painel apresentado é possível perceber as estatísticas de tempo de visualização, quantidade de visualizações, números de inscritos, tempo de exibição, duração média das visualizações, pessoas que gostaram e pessoas que não gostaram, bem como comentários e compartilhamentos. Ao cruzar essas métricas e analisá-las o docente consegue pensar em ajustes e reconfigurações de formatos e conteúdo para a página e aulas.

Nas duas imagens que seguem é possível perceber com detalhes as métricas sinalizadas: 




Figura 8 - Painel de estatísticas da página

Vale lembrar também que as estatisticas permitem inclusive identificar os locais mais acessados de forma global, por país, o gênero da audiência, a origem do trafêgo (site, Google, Whatsapp, Insatagram, Facebook, etc) e locais de reprodução.

Esses dados permitem ao professor pensar também o tom e canal de divulgação do material, permitindo maios assetividade no compartilhamento e influenciando o engajamento do aluno.

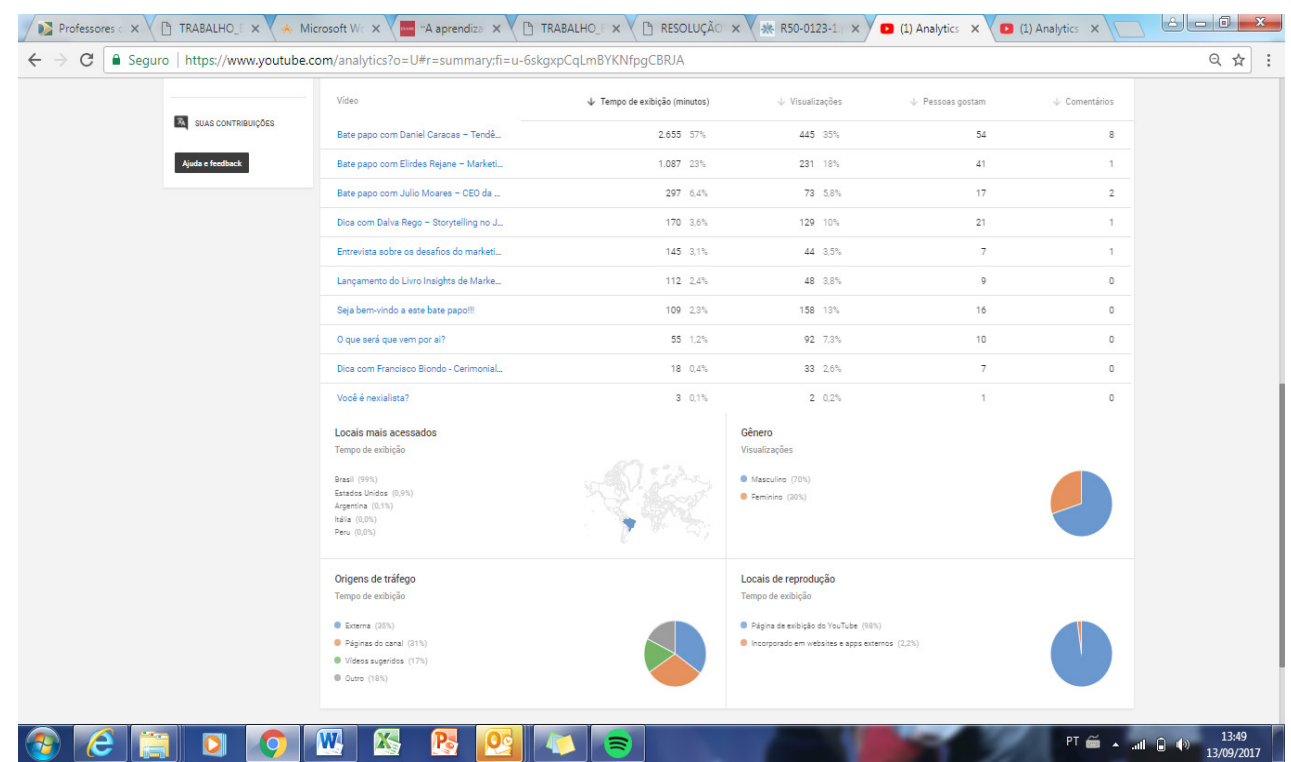

Figura 9 - Painel de estatísticas detalhado da página

O uso do Youtube como ferramenta de apoio ao docente e processo de ensino 
aprendizado é enriquecedor dado a sua caracteristista de estimular os diversos sentidos do aluno, a facilidade da compreensão cognitiva e o envolvimento interacional. Moran advoga que:

A força da linguagem audiovisual está no fato de ela conseguir dizer muito mais do que captamos, de ela chegar simultaneamente por muito mais caminhos do que conscientemente percebemos e de encontrar dentro de nós uma repercussão em imagens básicas, centrais, simbólicas, arquetípicas, com as quais nos identificamos ou que se relacionam conosco de alguma forma. (MORÁN, 2000, p. 34).

A inclusão do Youtube como ferramenta de ensino consente integrar às aulas uma linguagem mais próxima à realidade dos alunos e corrobora na condução do processo de assimilação de maneira leve e descontraída, provocando debates sobre o tema abordado, uma vez que as pessoas costumam se sentir mais à vontade quando falam sobre assuntos comuns de seu cotidiano. Essa mesma dinâmica ocorre com a plataforma digital Facebook, que também permite a utilização como um ambiente virtual de aprendizado, sendo demonstrando do capítulo a seguir.

\section{CONSIDERAÇÕES FINAIS}

A sociedade hoje se encontra sustentada pela tecnologia, tendo as redes sociais como um braço da cultura e oferecendo como conteúdo dois elementos básicos: informação e entretenimento. A permanente evolução do espaço web proporcionou nos últimos anos diferentes ferramentas, ambientes e plataformas que se fazem presentes na rotina da população. Tal fenômeno tornou a sociedade mais conectada e conseguiu unir as pessoas em grupos digitais: são aplicativos, redes sociais e espaços de interação que garantem conexão 24 horas por dia, 7 dias por semana e 360 dias por ano.

Como apresentado neste artigo, ao utilizar a mídia digital na educação, o docente está reforçando competências contextualizadas à sociedade contemporânea, remodelando inclusive a maneira de observar e produzir conhecimento e saberes. É possível também facilitar o processo de consumo do conteúdo por meio do mobile onde o aluno poderá 
assistir aos vídeos em qualquer local bastando ter disponível uma internet.

Utilizando o Youtube como um ferramenta de colaboração do ensino de é possível trabalhar de forma mais empática, leve e atual o conteúdo em sala de aula, potencializando a estratégia pedagógica e adicionando significados ao ensino e aprendizagem. A plataforma de vídeo já faz parte da realidade, e por meio dela, surge novas situações que envolvem complexidades no que se refere à comunicação na sociedade atual e principalmente quando se visa o processo educativo.

\section{REFERÊNCIAS}

ANDRADE, A. Uso(s) das novas tecnologias em um programa de formação de professores: possibilidades, controle e apropriações. 2007.192 f. Dissertação (Mestrado em Educação) - Faculdade de Educação, Universidade de São Paulo, São Paulo. 2007.

ANDRADE, A. L. Pensamento Sistêmico: um roteiro básico para perceber as estruturas da realidade organizacional. Revista Eletrônica de Administração, v. 3, n. 1, jun. 1998.

BURGESS, J.; GREEN, J. YouTube e a revolução digital: como o maior fenômeno da cultura participativa transformou a mídia e a sociedade. São Paulo: Aleph, 2009.

CHAMUZCA, M. Relações Públicas Digitais: o pensamento nacional de relações públicas interfacetado pelas tecnologias digitais. São Paulo: Edições VNI, 2011.

FAVA, R.. Educação 3.0: aplicando o PDCA nas instituições de ensino. São Paulo: Saraiva, 2014.

LÉVY, P. Cibercultura. São Paulo: Editora 34, 2009. 
MARTÍN-BARBERO, J. Os exercícios do ver: hegemonia audiovisual e ficção televisiva. São Paulo: SENAC, 2001.

MORÁN, J. M. Leituras dos meios de comunicação. São Paulo: Pancast, 1993.

Ensino e aprendizagem inovadores com tecnologias audiovisuais e telemáticas. In: MORAN, J. M.; MASETTO, M. T.; BEHRENS, M. A. Novas tecnologias e mediação pedagógica. Campinas, SP: Papirus, 2000.

MOURA, A.; CARVALHO, A. A. Podcast: para uma aprendizagem ubíqua no Ensino Secundário. 8th Internacional Symposium on Computer Education. Universidad de León, León, 2007.

NEVES, R. O novo mundo digital você está nele. São Paulo: Editora Relume Dumara, 2007.

VALENTE, J. A. Diferentes usos do computador na educação. 2012. Disponível em: <http:// nied.unicamp.br/publicacoes/separatas/Sep1.pdf>. Acesso em: 19 ago. 2017.

KAMERS, J. N. O Youtube como ferramenta pedagógica no ensino de Física. Florianópolis: Universidade do Estado de Santa Catarina, 2013. 